\title{
COVID-19 Outbreak and Oncological Surgery Practice
}

\author{
Merve Tokocin $^{1} \cdot$ Talar Vartanoglu Aktokmakyan $^{1}$ (D) $\cdot$ Yuksel Altinel $^{1} \cdot$ Ahmet Akbas $^{1}$
}

Received: 1 June 2020 / Accepted: 21 September 2020 / Published online: 26 September 2020

(C) Indian Association of Surgical Oncology 2020

\begin{abstract}
The emergence of COVID-19 has caused a global public health emergency. With the World Health Organization (WHO) reporting the novel coronavirus outbreak a pandemic, the focus is needed on the influence of this rapidly spreading viral infection on cancer patients. In this study, we aimed to address cancer-related operations during the COVID-19 outbreak. We retrospectively reviewed 26 patients who had undergone cancer surgeries admitted from March 13 to May 13, 2020, during the COVID-19 epidemic at Istanbul Bagcilar Training and Research Hospital, as a pandemic hospital. A total of 26 cases of COVID-19 were enrolled in the study. Seventeen (65\%) were female, and 9 (35\%) were male. The mean age was 52.4 (range 28-74). The mean body mass index (BMI) is $27.8 \mathrm{~kg} / \mathrm{m}^{2}$ (range 17.6-34.0). Eight of them had comorbidities. 7 patients needed an intensive care unit (ICU). Only one patient was COVID-19 positive in the PCR test, while the others were negative. In addition to this patient, 3 other patients were COVID-19 positive on computed tomography (CT). The patients included in this study underwent various oncologic surgery procedures. While 24 patients were discharged without any problems, 2 patients developed complications. Due to respiratory problems, the patient could not get out of intensive care and died on the sixth postoperative day. It is the obligation of the institutions and the medical staff to reassure patients by creating safe postoperative surgical environments free of COVID-19. Surgeon leaders need to synthesize actual data to make the best decisions for their cancer patients.
\end{abstract}

Keywords Cancer $\cdot$ Cancer surgery $\cdot$ COVID-19

\section{Introduction}

The emergence of COVID-19 has caused a global public health emergency. The virus was named severe acute respiratory syndrome coronavirus 2 (SARS-CoV-2) and has a phylogenetic similarity to SARS-CoV-1 that caused the SARS pandemic in 2002 [1]. According to the World Health Organization (WHO), as of 10 a.m. CEST 20 May 2020, 4,789,205 people were infected while 318,789 people have died so far [2]. With the World Health Organization (WHO) reporting the novel coronavirus outbreak a pandemic, the focus is needed on the influence of this rapidly spreading viral infection on cancer patients [3, 4]. Patients with cancer are more susceptible to infection than are individuals without cancer because of malignancy and anticancer therapy result in an immunosuppressive situation [5]. Limited studies and

Talar Vartanoglu Aktokmakyan talarim@gmail.com

1 Istanbul Bagcilar Training And Research Hospital, Merkez Mah, 34200 Istanbul, Turkey researches respecting the readiness program for cancer patients during an infectious pandemic exist. In this study, we aimed to address cancer-related operations during the COVID-19 outbreak.

\section{Material and Methods}

We retrospectively reviewed 26 patients who had undergone cancer surgeries admitted from March 13 to May 13, 2020, during the COVID-19 epidemic at Istanbul Bagcilar Training and Research Hospital, as a pandemic hospital. Laboratory confirmation of SAR-CoV-2 was done by quantitative RTPCR on samples from the respiratory tract, which was performed by the local health authority as described. The study was reviewed and approved by the Ethical Committee of participating institutes and the Ministry of Health. Oral consent was obtained from all participating patients. The clinical outcomes of these operative patients were monitored up to May 18, 2020, the final date of follow-up, when all the patients were discharged. The patients included in this study underwent various oncologic surgery procedures. 


\section{Results}

A total of 26 cases of COVID-19 were enrolled in the study (Table 1). Seventeen (65\%) were female, and nine (35\%) were male. The mean age was 52.4 (range 28-74). The mean body mass index (BMI) is $27.8 \mathrm{~kg} / \mathrm{m}^{2}$ (range 17.6-34.0). Eight of them had comorbidities like hypertension (HT), diabetes mellitus (DM), chronic artery disease (CAD), atrial fibrillation (AF), and chronic kidney disease (CKD) (Table 2).

7 patients needed intensive care unit (ICU) (Table 3). Three gastric cancer patients, two colon cancer patients, and a thyroid cancer patient were followed in ICU due to their comorbidities. One colon cancer patient was followed in ICU due to the severity of her operation. Due to an invasive transverse colon tumor to the pancreas, to the stomach, to the jejunum, and to the ileum, large unblock resection was performed. Only this patient was COVID-19 positive in the PCR test, while the others were negative. In addition to this patient, 3 other patients have COVID-19 positive on computed tomography (CT).

The patients included in this study underwent various oncologic surgery procedures (Table 4), while 24 patients were discharged without any problems, and 2 patients developed complications. One of these two patients had transverse colon cancer and underwent emergency surgery, and the other had thyroid cancer and underwent elective surgery. In the transverse colon tumor patient, our only COVID-19-positive patient, pancreatic fistula developed as a complication in the postoperative period, but there was no respiratory problem and was discharged after the follow-up period. On the other hand, as a complication, hematoma developed in the postoperative period in the thyroid cancer patient with renal transplant and suspected tomography and was re-operated on the same day. Due to respiratory problems, the patient could not get out of intensive care and died on the sixth postoperative day. Six of the 26 patients ( $25 \%$ ) were operated on a palliative operation rather than a curative operation.

\section{Discussion}

The coronavirus disease is a novel viral disease that has spread rapidly worldwide, becoming a pandemic. Approximately

Table 1 Characteristics of patients

\begin{tabular}{ll}
\hline Patients & $26(n)$ \\
Female/male & $17 / 9$ \\
Mean age & $52,4(28-74)$ \\
Mean BMI & $27,8 \mathrm{~kg} / \mathrm{m}^{2}(17,6-34,0)$ \\
Comorbid patients & 8 \\
ICU-needed patients & 6 \\
Complication & 2 \\
Mortality & 1 \\
\hline
\end{tabular}

Table 2 Comorbidities of patients

Comorbidities

\begin{tabular}{ll}
$\mathrm{HT}$ & 6 \\
$\mathrm{DM}$ & 3 \\
$\mathrm{CAD}$ & 2 \\
$\mathrm{AF}$ & 1 \\
$\mathrm{CKD}$ & 1 \\
\hline
\end{tabular}

$20-30 \%$ of patients will require intensive care unit (ICU) admission due to acute respiratory distress syndrome [6]. Therefore, elective surgical caseload was tried to be significantly reduce the number to provide more intensive care and hospital bed capacity. Besides, surgical procedures were tried to limit the life-threatening situations requiring urgent surgical treatment. Regarding cancer surgery, most procedures have been postponed. However, it should be well considered that cancer cannot be postponed or delayed. Due to the potential negative impact of treatment delays on prognosis, surgical and oncological societies have published guidelines to identify ideal clinical situations and have suggested alternative management strategies to the standards of care in clinical situations [7].

In this study, we experienced two complications and one mortality. The cause of the mortality was not related to COVID-19, and also to the complication. The importance of risk and benefit for active intervention in the cancer population must be individualized. Postponing elective surgery for cancer patients with low risk of progression should be considered on a case-by-case basis.

The decision to suspend or cancel elective surgical operations should not only be made on the risk of COVID-19 spread. The surgical team should consider risks of cancer, vascular disease, organ failure, and progression of the disease [8]. In our study, palliative surgeries, which miss the chance of curative surgery for possible late admission due to the COVID-19 outbreak, stand out. In this epidemic period, patients started to apply to the hospital late due to fear of transmission despite their complaints. Besides, we think that the elective surgeries' displacement due to bed deprivation has led to these results.

It is the obligation of the institutions and the medical staff to reassure patients by creating safe postoperative surgical

Table 3 Parameters about COVID-19 infection

\begin{tabular}{lll}
\hline Parameters & & \\
\hline Symptomatic patients & Fever & 0 \\
& Cough & 1 \\
& Dyspnea & 0 \\
Positive COVID-19 test & & 1 \\
Positive BT findings & & 4
\end{tabular}


Table 4 Type of cancer operations

Elective operations during COVID-19 pandemic $(n=26)$

Curative operations

\begin{tabular}{lc} 
Abdominoperineal resection & 1 \\
Anterior resection/ laparoscopic anterior resection/low anterior resection & $2 / 2 / 1$ \\
Total thyroidectomy & 2 \\
Gastrectomy total & 1 \\
Modified radical mastectomy & 4 \\
Segmental mastectomy + centinal lymph node dissection & 6 \\
Primer gastric repair & 1 \\
Gastrectomy subtotal & 1 \\
Debulking & 2 \\
Gastrostomy & 1 \\
Transverse colon resection* & 1 \\
\hline
\end{tabular}

* denote only COVID-19-positive patient

environments free of COVID-19 as much as possible. So that preoperative screening of all patients for COVID-19 is extraordinary. When the COVID-19 infection is positive, elective cancer surgery should be analyzed according to the patient's benefit, due to the risk of postoperative complications and possibly the risk of death.

In a retrospective study along with the 2009 influenza A (H1N1) virus pandemic, the cancer patient population was at a higher incidence of pneumonia $(66 \%)$ and 30-day mortality (18.5\%) compared with the general population [9]. A new small case series study that evaluated COVID-19 in cancer patients found that patients with cancer had worse outcomes from COVID-19 than did other individuals without cancer [5]. Although the number of cases is limited, the number of studies remarking the opposite is also very weak, and we assume that pandemic periods should be examined and analyzed more from this perspective.

\section{Compliance with Ethical Standards}

The study was reviewed and approved by the Ethical Committee of participating institutes and the Ministry of Health.

Conflict of Interest The authors declare that they have no conflict of interest.

\section{References}

1. Guan WJ, Ni ZY, Hu Y, Liang WH, Ou CQ, He JX, Liu L, Shan H, Lei CL, Hui DSC, du B, Li LJ, Zeng G, Yuen KY, Chen RC, Tang CL, Wang T, Chen PY, Xiang J, Li SY, Wang JL, Liang ZJ, Peng
YX, Wei L, Liu Y, Hu YH, Peng P, Wang JM, Liu JY, Chen Z, Li G, Zheng ZJ, Qiu SQ, Luo J, Ye CJ, Zhu SY, Zhong NS, China Medical Treatment Expert Group for Covid-19 (2020 [Epub ahead of print]) Clinical characteristics of coronavirus disease 2019 in China. N Engl J Med 382:1708-1720

2. Coronavirus disease 2019 (COVID-19) Situation report - 121, WHO, 2020, 10 AM CEST 20 May 2020. (https://www.who.int/ docs/default-source/coronaviruse/situation-reports). Accessed 11 Mar 2020

3. World Health Organization. WHO Director-General's opening remarks at the media briefing on COVID-19, March 11, 2020. (Available at https://www.who.int/dg/speeches/detail/who-directorgeneral-s-opening-remarks-at-the-media-briefing-on-covid-19-11march-2020. Accessed Mar 11, 2020)

4. World Health Organization. Coronavirus disease (COVID-19) pandemic. (Available at https://www.who.int/emergencies/diseases/ novel-coronavirus-2019. Accessed Mar 11, 2020)

5. Liang W, Guan W, Chen R, Wang W, Li J, Xu K, Li C, Ai Q, Lu W, Liang H, Li S, He J (2020) Cancer patients in SARS-CoV-2 infection: a nationwide analysis in China. Lancet Oncol 21:335-337

6. Onder G, Rezza G, Brusaferro S (2020) Case-fatality rate and characteristics of patients dying in relation to COVID-19 in Italy. JAMA. https://doi.org/10.1001/jama.2020.4683

7. Tuech JJ, Gangloff A, Di Fiore F et al (2020) Strategy for the practice of digestive and oncological surgery during the Covid-19 epidemic. J Visc Surg S1878-7886(20):30070-30079. https://doi.org/10.1016/j. jviscsurg.2020.03.008

8. American College of Surgeons COVID-19: guidance for triage of non-emergent surgical procedures. https://www.facs.org/about-acs/ covid-19/information-for-surgeons/triage. Accessed 11 Mar 2020

9. Dignani MC, Costantini P, Salgueira C et al (2014) Pandemic 2009 influenza $\mathrm{A}(\mathrm{H} 1 \mathrm{~N} 1)$ virus infection in cancer and hematopoietic stem cell transplant recipients; a multicenter observational study. F1000Res 3:221

Publisher's Note Springer Nature remains neutral with regard to jurisdictional claims in published maps and institutional affiliations. 